\section{KAMUS PENDAMPING AKUNTANSI DAN PERBANKAN UNTUK SISWA DAN MAHASISWA}

Dalam Kebutuhan dunia kerja, menuntut kita untuk selalu berpikir kreatif dan inovatif sesuai dengan perkembangan zaman. Dimana kita harus selalu mengupdate setiap pergerakan informasi bidang ilmu keakuntansian maupun perbankan. Bekerja menjadi seorang akuntan di dunia usaha dan Industri maupun perbankan tentu harus bisa memahami berbagai istilah atau komponen-komponen dari bidang kerja itu sendiri, sehingga proses kerja dapat tercipta dengan baik. Dari hal demikian didalam buku ini akan tersaji mengenai istilah yang ada dalam keakuntansian maupun perbankan. Buku Kamus Pendamping Akuntansi dan Perbankan ini adalah sebagai informasi penambah pengetahuan, dimana istilah-istilah maupun berbagai definisi yang tersaji di rangkum oleh penulis dari berbagai literatur menjadi satu kemasan yang sederhana. Buku ini tidak hanya bermanfaat sebagai literasi bahan bacaan akan tetapi sebagai pemahaman dalam pemaknaan sebagai informasi dalam mempermudah proses pembelajaran dengan harapan menjadi ahli dalam hal keakuntansian maupun perbankan nantinya. Buku ini sangat bermanfaat buat siswa dan mahasiswa sebagai pendampingan dalam menempuh pendidikan dikejuruan Akuntansi maupun perbankan. Di dalam buku ini menyajikan Istilah-istilah dalam Akuntansi, Definisi Istilah Akuntansi Keuangan, Definisi istilah umum Perbankan dan Definisi istilah Perbankan Syariah. Buku ini dikemas dalam kemasan yang simple sehingga mudah untuk dibaca, dipelajaridan dipahami.

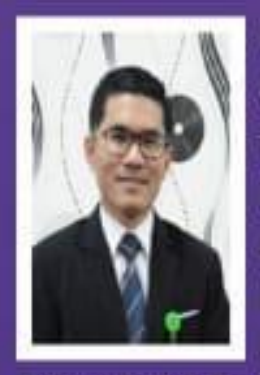

Penulis lahir 02 Februari 1986 di Kota Banjarmasin provinsi Kalimantan Selatan, menyelesaikan pendidikan sekolah Dasar SDN Kuin Cerucuk 4 tahun 1999, Sekolah lanjutan Tingkat Pertama SLTP Negeri 15 Banjarmasin tahun 2002, Sekolah SMKN 1 kota Banjarmasin jurusan Akuntansi tahun 2005, S1 Akuntansi tahun 2011 di Sekolah Tinggi Ilmu Ekonomi Pancasetia Banjarmasin dan S2 Manajemen Konsentrasi Manajemen Keuangan tahun 2014 di Sekolah Tinggi Ilmu Ekonomi Pancasetia Banjarmasin . Sertifikasi Nasional Bergelar Profesi Lisensi BNSP Certified Risk Associate dan Certified Risk Professional tahun 2020. Pengalaman Kerja penulis pernah sebagai penyiar radio Nirwana Group (Pelangi Fm) pada Januari tahun 2006 Januari 2012, Audit Internal Wira Toyota Banjarmasin pada Maret - Juli tahun 2012, Berkarier di PT Bank BRISyariah KC Banjarmasin pada Desember tahun 2012September 2017, Dosen Luar Biasa Akademi Sekertaris Manajemen Indonesia Citra Nusantara sejak tahun 2017 dan Aktivitas keseharian penulis sebagai Dosen Tetap Program Studi Sarjana Akuntansi Fakultas Humaniora Universitas Sari Mulia.
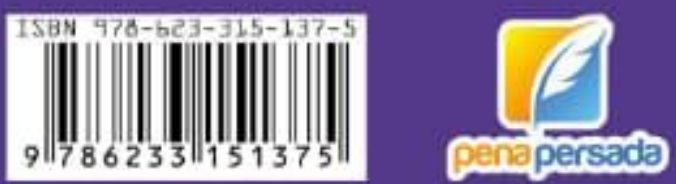

YUSRI, SE., MM., CRA., CRP
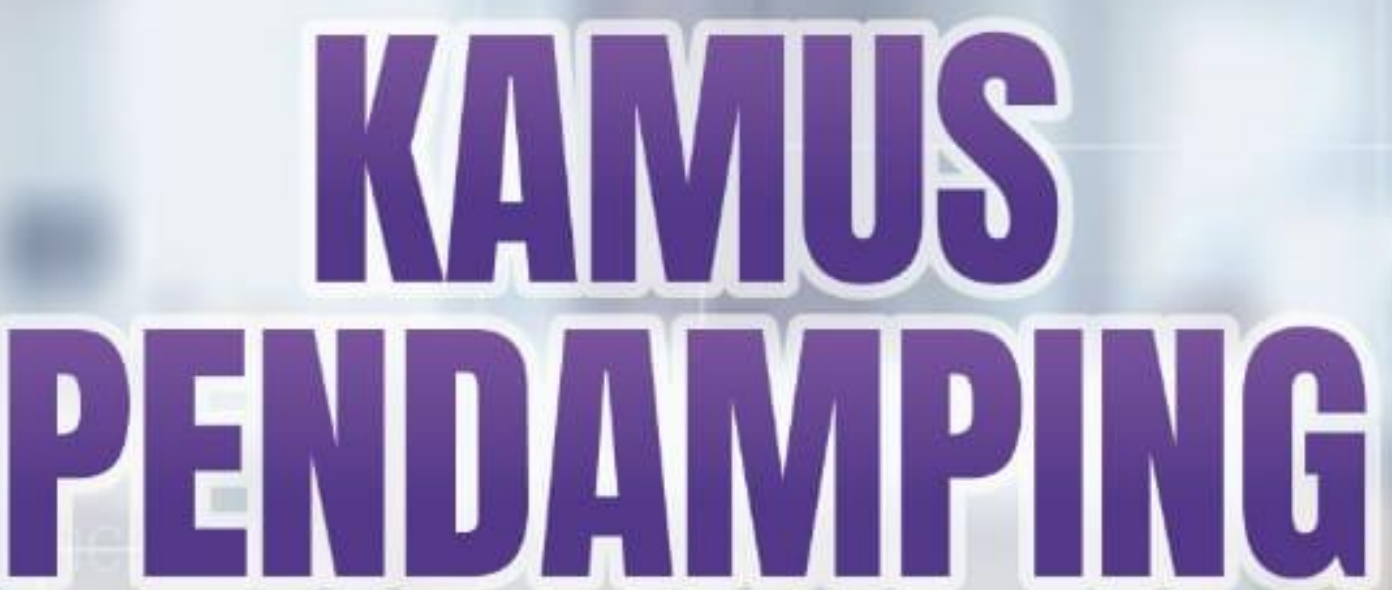

AKUNTANSI DAN PERBANKAN UNTUK SISWA DAN MAHASISWA 
KAMUS PENDAMPING AKUNTANSI DAN

PERBANKAN UNTUK SISWA DAN MAHASISWA

YUSRI, SE., MM., CRA., CRP

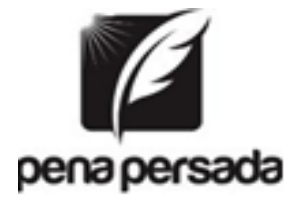

CV. PENA PERSADA 


\section{KAMUS PENDAMPING AKUNTANSI DAN PERBANKAN UNTUK SISWA DAN MAHASISWA}

Penulis :

YUSRI, SE., MM., CRA., CRP

ISBN : 978-623-315-137-5

\section{Design Cover :}

Retnani Nur Briliant

Layout :

Hasnah Aulia

Penerbit CV. Pena Persada

Redaksi :

Jl. Gerilya No. 292 Purwokerto Selatan, Kab. Banyumas Jawa

Tengah

Email : penerbit.penapersada@gmail.com

Website : penapersada.com

Phone : (0281) 7771388

Anggota IKAPI

All right reserved

Cetakan pertama : 2021

Hak cipta dilindungi oleh undang-undang.

Dilarang memperbanyak buku ini dalam bentuk dan cara apapun tanpa ijin penerbit 


\section{KATA PENGANTAR}

Puji dan Syukur saya ucapkan kepada Tuhan yang maha Esa karena berkat rahmat dan ridho-Nya lah yang telah senantiasa memberikan kesehatan, rezeki dan kesempatan untuk berkarya menjadi yang lebih baik.

Terimakasih atas support teman-teman sewaktu bekerja diperusahaan dulu, baik di perusahaan swasta maupun di perbankan dan teman-teman rekan kerja yang ada di pendidikan yang membantu dalam penyusunan hingga terwujudnya buku ini.

Inspirasi buku ini berawal dari catatan-catatan kecil saya diwaktu kuliah dulu dan beberapa buku-buku sewaktu bekerja diperusahaan swasta maupun diperbankan, dimana sebelum menjadi seorang dosen, saya adalah seorang accounting dan juga banker Banyak hal istilah - istilah asing bidang Akuntansi dan keuangan yang dulu tidak saya pahami dan tidak saya ketahui, kemudian terkadang di tulis dalam note kecil yang terpisah-pisah dan buku-buku yang begitu banyaknya. Dari hal demikian terpikir dalam diri saya untuk merangkum istilah tersebut dalam kemasan yang simple dan mudah dipahami yang mana bisa digunakan sebagai bahan bacaan dalam memudahkan pemahaman yang lebih baik. Istilah-istilah ini sangat penting untuk diketahui terutama bagi seorang pelajar maupun mahasiswa yang belajar mengenai dunia ke akuntansian maupun perbankan sebagai pendamping dalam menjalani proses pembelajaran maupun sebagai bekal bekerja nantinya.

Buku ini tentu masih ada kekurangan dan perlu banyak direvisi untuk tahap pengembangan selanjutnya. Namun dengan hadirnya buku ini dengan kemasan yang masih sangat sederhana semoga bisa menambah pengetahuan. 
Anda dalam menempuh pendidikan dan proses pembelajaran terutama di jurusan Akuntansi dan keuangan maupun perbankan.

Banjarmasin, Januari 2021

Yusri, SE., MM., CRA., CRP 


\section{DAFTAR ISI}

KATA PENGANTAR ............................................................... iii

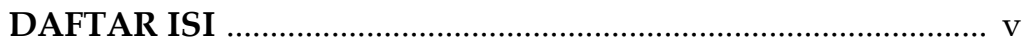

ISTILAH-ISTILAH DALAM AKUNTANSI .............................. 1

DEFINISI ISTLAH AKUNTANSI KEUANGAN ...................... 33

DEFINISI ISTILAH UMUM PERBANKAN .............................. 53

DEFINISI ISTILAH PERBANKAN SYARIAH ........................... 68

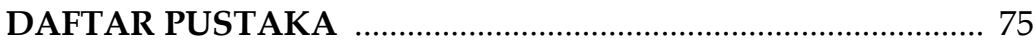


KAMUS PENDAMPING AKUNTANSI DAN PERBANKAN UNTUK SISWA DAN MAHASISWA AKUNTANSI \& PERBANKAN 


\section{ISTILAH ISTILAH DALAM AKUNTANSI}

A

ACCOUNT

ACCOUNT RECEIVABLE

ACCOUNT FROM

ACCOUNT NOT CURRENT

ACCOUNT PAYABLE

ACCOUNT PAYABLE LEDGER

ACCOUNT RECEIVABLE

STATEMENT

ACCOUNT PAYABLE SUBSIDIARY

LEDGER

ACCOUNTANT

ACCOUNTANT FEE EXPENSE

ACCOUNTANT PUBLIC

ACCOUNTING

ACCOUNTING ASSUMPTION

ACCOUNTING CYCLE

ACCOUNTING DATA

ACCOUNTING DEPARTMENT

ACCOUNTING EQUATION

ACCOUNTING INCOME

ACCOUNTING INFORMATION

ACCOUNTING INSTRUCTION

ACCOUNTING MANAGEMENT

ACCOUNTING METHOD

ACCOUNTING PERIOD
(Perkiraan)

(Piutang Dagang/usaha)

(Bentuk Perkiraan)

( Pos-pos yang tidak

lancar )

(Hutang Lancar/ hutang

usaha)

(Buku besar hutang )

(Daftar piutang usaha)

(Buku tambahan piutang)

(Akuntan)

(Biaya akuntan)

(Akuntan publik)

(Akuntansi)

(Asumsi akuntansi)

(Sirklus akuntansi )

(Data akuntansi)

(Departemen akuntansi)

(Persaman akuntansi)

(Laba akuntansi)

(Informasi akuntansi)

(Intruksi akuntansi)

(Manajemen akuntansi)

(Metode akuntansi)

(Periode akuntansi) 
ACCOUNTING PRINCIPLE

ACCOUNTING PROCEDURE

ACCOUNTING RESPONSIBILITY

ACCOUNTING SYSTEM

ACCOUNTS INTER COMPANY

ACCRUED EXPENSE

ACCRUED EXPENSE PAYABLE ACCRUED PAYROLL PAYABLE ACCRUED INTERS PAYABLE ACCRUED REVENUE

ACCRUED TAX PAYABLE

ACCRUED WAGES PAYABLE

ACCUMULATED DEPLETION

ACCUMULATED DEPRECIATION

ACTUAL AMOUNT

ACTUAL COST

ACTUAL FACTORY OVERHEAD

ACTUAL LIABILITY

ACTUAL PRICE

ACTUAL QUANTITY

ADMINISTRATIVE AND GENERAL EXPENSE
(Akuntansi dasar)

(Prosedur akuntansi)

(Akuntansi pertanggung jawaban)

(Sistem akuntansi )

(Rekening antar

perusahan)

( Biaya yang akan di bayar/biaya-biaya yang masih harus dibayar )

(Beban terhutang)

(Utang gaji)

(Bunga terhutang)

(Pendapatan yang akan

diterima/pendapatan

yang masih harus

ditagih)

(Hutang pajak)

(Upah terhutang)

(Akumulasi deplesi)

(Akumulasi penyusutan)

(Jumlah sesungguhnya )

(Biaya sesungguhnya)

(Beban overhead

sesungguhnya)

(Hutang nyata)

(Harga sesungguhnya)

(Kwalitas sesungguhnya)

(Beban administrasi dan umum) 
ADJUSTED BALANCE

ADJUSTED TRIAL BALANCE

ADJUSTING ENTRIES

ADDITIONAL COST

ADVANCE FROM CUSTOMER

ADVANCE ACCOUNTING

ADVERTISING EXPENSE

ADVERSE OPINION

ALLOWANCE FOR INVENTORY

DECLINE TO MARKET

ALLOWANCE METHOD

ALLOWANCE ACCOUNT

ALLOWANCE FOR BAD DEBT

ALLOWANCE FOR DOUBT

FULL ACCOUNT

ALLOWANCE FOR OVER-

VALUATION OF BRANCH

MERCHANDISE

AMORTIZATION

APPLIED FACTORY OVERHEAD COST

ANNUAL REPORT

ASSET

ASSET APPROACH

ASSET ACCOUNT

AUDIT FEE
(Saldo setelah penyesuaian)

(Neraca saldo penyesuaian)

(Ayat jurnal penyesuaian)

(Biaya tambahan)

(Uang muka langganan)

(Akuntansi lanjutan)

(Biaya iklan)

(Pendapatan tidak wajar )

(Cadangan penurunan nilai persediaan)

( Metode cadangan)

(Perkiraan cadangan)

(Cadangan piutang tak

tertagih)

(Cadangan piutang ragu-

ragu)

( Cadangan kenaikan harga barang cabang )

(Penyusutan atas harta tak berwujud)

(Biaya overhead yang

dibebankan)

(Laporan tahunan)

( Harta )

(Pendekatan aktifa)

(Perkiranan harta)

(Pendapatan audit) 
ASSUME

AUDIT EXPENSE

AUDIT PROGRAMME

AUDIT PROCESS

AUDIT PLANNING

AUDITOR

AUDITING

AVERAGE METHOD
(Asumsi)

(Biaya audit)

(Program pemeriksaan)

(Proses pemeriksaan)

(Rencana pereiksaan)

(Pemerikasa keuangan)

(Pemeriksaan keuangan)

( Metode rata-rata)

B

BALANCE SHEET

BALANCE PER BANK

BALANCE PER BOOK

BALANCE SHEET ACCOUNT

BALANCE AMOUNT

BANK PAYABLE

( Neraca )

(Saldo menurut bank)

(Saldo menurut buku)

(Perkiraan neraca)

(keseimbangan jumlah)

(Hutang bank)

BALANCE BEFORE LIQUIDATION (Saldo sebelum likuidasi)

BANK RECONCILIATION

BANK SERVICE CHARGE

(Reconsiliasi bank)

(Biaya administrasi bank /

biaya layanan bank )

BANK STATEMENT

(Rekening Koran )

Bed Debts Expense

BIN CARD

(Beban kerugian piutang )

BASIC FINANCIAL STATEMENT

( Kartu gudang )

BEGINNING BALANCE

(Laporan keuangan pokok )

( Saldo awal )

BETTERMENT

(Perbaikan)

BONDS PAYABLE

BOOK VALUE

BOOK VALUE OF ASSET

(Utang obligasi )

( Nilai buku )

(Nilai buku aktifa)

BOOK VALUE PER SHARE

(Nilai buku per saham )

BRANCH

( Cabang )

BRANCH MERCHANDISE

( Barang dagangan cabang )

BRANCH PROFIT

(Keuntungan cabang ) 
BREAK EVEN

BREAK EVEN PIONT

BREAK EVEN SALES

BUDGET

BUDGET VARIANCE

BUDGET FLEXIBLE

BUDGET FIXED

BUDGET CYCLE

BUDGET BALANCE SHEET

BY PRODUCT

BUILDING

BUSINESS ENTITY
( Pulang pokok/seri/

impas )

(Titik pulang pokok/titik impas )

(Penjualan pulang pokok/penjualan impas)

(Anggaran )

(Selisih anggaran)

(Anggaran flexsibel )

(Anggaran tetap )

(Siklus Anggaran)

( Anggaran neraca)

( Produksi sampingan)

(Gedung )

(Kesatuan usaha)

C

CAPITAL

CAPITAL STATEMENT

CAPITAL STOCK

$\mathrm{CASH}$

CASH BUDGET

( Modal )

( Laporan perubahan

modal )

( Modal saham )

( Kas )

CASH COUNT

(Anggaran kas )

(Perhitungan kas )

CASH DISBURSEMENT JOURNAL (Jurnal pengeluaran kas)

CASH DISCOUNT

( Potongan yang diberikan atas pembayaran tunai )

CASH FLOW

( Alur kas )

CASH FLOW CYCLE

(Siklus alur kas )

CASH IN BANK

(Kas dalam bank/kas di bank )

CASH ON HAND 
CASH IN TRANSIT

CASH PAYMENT JOURNAL

CASH RECEIPT JOURNAL

CASH SALES

CLOSING ENTRIES

Classifying

COST

COST ACCOUNTING

COST OF GOODS AVAIBLE FOR SALES

COST OF GOODS MANU-

FACTURED

COST OF GOODS SOLD

CREDIT MEMORANDUM

CURRENCY

CURRENCY ASSET

CURRENCY LIABILITIES
( Kas dalam perjalanan )

( Buku kas pengeluaran)

(Buku kas penerimaan )

( Penjualan tunai )

(Ayat jurnal penutup )

( Proses penggolongan )

( Biaya )

(Akuntansi biaya )

( Harga pokok barang tersedia untuk dijual )

( Harga pokok produksi )

( Harga pokok barang yang

di jual (Harga Pokok

Penjualan)

( Nota kredit )

( Mata uang )

( Harta lancar)

(Hutang jangka

pendek/Utang Lancar )

D

DEBIT NOTE

DEBIT BALANCE

DEDUCTION

DEFECTIVE GOODS

DEFERRED GROS PROFIT ON

REALIZATION

DELIVERY EXPENSE

Delivery equipment

DEPOSIT SLIP

6
( Nota debet)

( Saldo debet )

(Pengurangan)

(Produk rusak)

( Laba kotar yang belum

direalisasikan )

( Biaya pengangkutan )

(peralatan angkutan)

(Bukti setoran ) 
DEPRECIATION

DEPRECIATION EXPENSE

DETERMINING DEPRECIATION

DIRECT COSTING

DIRECT DEPARTMENT

OVERHEAD EXPENSE

DIRECT EXPENSE

DIRECT LABOR COST BUTGET

DIRECT TAXES

DIRECT WRITE OFF

DISCOUNT

DISSOLUTION

DIVIDEND STOCK

DOUBLE ENTRY SYSTEM

DUE DATE

E

EARNED

EARNING AFTER INTEREST

AND TAXES

dan pajak)

EARNING AFTER TAX

ECONOMIC LIFE

ECONOMIC ORDER QUANTITY
(Penyusutan)

(Biaya penyusutan )

( Penetapan penyusutan)

( Penetapan biaya

langsung )

(Beban/biaya overhead departemen langsung )

(Biaya langsung)

(Biaya anggaran buruh

langsung)

(Pajak langsung)

(Penghapusan langsung )

( Potongan harga )

(Pembubaran )

(Deviden saham )

( Sistem pembukuan

berpasangan )

(Tanggal jatuh tempo)

( Pendapatan )

(Pendapatan sesudah bunga

(Pendapatan sesudah pajak)

(Umur ekonomi)

( Jumlah pembelian

optimal )

EMERGENCY WORKING CAPITAL (Modal kerja darurat )

EMPLOYEE EARNING STA-

TEMENT

( Laporan gaji karyawan )

END OF MONTH TRIAL 
BALANCE

ENDING BALANCE

ENDING INVENTORY

ENTERTAIMENT EXPENSE

ENTRY

EQUIPMENT

EQUITIES

EQUITY IH INCOME OF

SUBSIDIARY COMPANY

ESTIMATE VALUE

ESTIMATED GROSS PROVIT

EVIDENCE

EXCEPT

EXCESS OF COST OVER BOOK

VALUE OF SUBSIDIARY INTEREST (Selisih lebih harga pokok di

EXCESS VALUE

EXCHANGE RATE

EXPECTED ACTUAL CAPACITY

EXPECTED RATE OF RETURN

EXPIRED

EXPENSE

EXTERNAL AUDIT

EXTRA ORDINARY GAIN

EXTRA ORDINARY LOSS

EXTRA ORDINARY REPAIRS

(EXTRA ORDINARY RETIREMENT)
( Daftar saldo akhir bulan )

( Saldo akhir )

(Persediaan akhir)

( Biaya entertain )

(Ayat)

( Peralatan )

( Kekayaan )

(Laba atas anak

perusahaan )

(Nilai taksir)

(Taksiran laba kotor)

(Bukti-bukti)

( Pengecualian ) atas nilai buku)

( Nilai lebih )

( Nilai tukar)

(Kapasitas yang

sesungguhnya di harapkan )

(Tingkat pengembalian yang

diinginkan)

( Kadarluasa )

( Biaya )

(Pemeriksaan ekternal )

(pembelajan yang luar

biasa)

(Kerugian yang luar biasa)

(Perbaikan luar biasa)

(Penarikan aktiva sebab luar biasa) 


\section{$\mathbf{F}$}

FINANSIAL STATEMENT

(Laporan Keuangan)

FISCAL YEAR

( Tahun pajak )

FIXED ASSET SUBSIDIARY LEDGE

(Buku tambahan harta tetap)

FIXED ASSET TURNOVER

(Perputaran harta tetap)

FIXED CAPITAL ASSET

(Modal kerja tetap)

FIXED CAST

FIXED EFFICENCY VARIANCE

(Biaya tetap)

(Penyimpangan effisiensi

yang tetap)

FIXED FACTORY OVERHEAD

(Overhead pabrik yang tetap)

FLEXIBLE BUDGET

(Anggaran yang berubahubah)

FLOOR

FLOW OF COST

FLOW OF DOCUMENT

(Batasan bawah)

FLOW OF FUNDS

FLOW OF WORK

(Aliran biaya)

(Peredaran dokumen)

(Aliran dana)

(Peredaran kerja)

FLOWCHART

(Daftar aliran)

FLUCTUALING METHO

(Metode fluktuasi )

FLUCTUATING FUND

(Dana berubah-ubah )

FOOT NOTE

(Catatan kaki)

FORECAST BALANCE SHEET

(Ramalan neraca)

FORECAST INCOME STATEMENT

(Taksiran rugi laba)

FORM

(Formulir)

FOUR COLLUMN COUNT

(Jurnal empat kolom)

FRAUD

(kecurangan)

FREIGHT IN

(Ongkos angkut pembelian)

FREIGHT ON MATERIAL

PURCHASAS

(Beban angkut pembelian bahan)

FREIGHT OUT 
FUNDS

FUNDS STATEMENT

FURNITURE \& FIXTURE

FUSION
(Dana)

(Laporan sumber dan

pengunan dana)

(Peralatan)

(Penggabungan)

G

GENERAL ACCOUNTING

(Akuntansi Umum)

GENERAL LEDGER

( Buku besar)

GENERAL JOURNAL

(Jurnal umum)

GENERAL AND ADMINISTRATIVE EXPENSE

(Biaya umum dan administrasi)

GENERAL EXAMINATION

(Pemeriksaan umum)

GENERAL ASSIGMENT

(Penegasan umum)

GOVERNMENT FINANCIAL

(Keuangan penerintah)

GOVERNMENT ACCUNTING

(Akuntansi pemerintah)

GROSS METHOD

(Metode Kotor)

GROSS LOSS

(Rugi kotor)

GROSS PROFIT

GROSS PROFIT ANALYSIST

(Laba kotor)

(Analisa laba kotor)

GROSS PROFIT METHO

(Metode laba kotor)

GROSS PROFIT ON SALE

(Laba kotor atas penjualan)

GROSS WORKING CAPITAL

GROUP CODE

(modal kerja kotor)

(Kode kelompok)

GO PUBLIK COMPONY

(Perusahan yang menjual

saham ke masyarakat)

H

HEATING AND LIGHTING

EXPENSE

(Biaya pemanasan dan

penerangan)

HIDDEN RESERVES

(Cadangan Rahasia) 
HISTORICAL COST

ACCOUNTING

HISTORICAL COST

HOME OFFICE

HORIZON ANALYST

HUMAN RESOURCE

ACCOUNTING
(Harga Perolehan Historis)

(Biaya Historis)

(Kantor Pusat)

(Analisa Mendatar)

(Akuntansi Sumber Daya Manusia)

(laba)

INCOME

INCOME BEFORE TAX /

EARNING BEFORE TAX

INCOME AFTER TAX / EARNING

AFTER TAX

INCOME FROM JOINT VENTURE

INCOME FROM OPERATION

INCOME SHARING AGREEMENT

INCOME STATEMENT

INCOME STATEMENT ACCOUNT

INCOME SUMMARY

INCREMENTAL COST

INDEPENDENT AUDITOR REPORT (Laporan pemeriksaan

INDIRECT EXPENSE

INDIRECT DEPARTEMENTAL

EXPENSE

INDIRECT FACTORY COST

INDIRECT LABOR bebas )

(Laba bersih sebelum pajak)

(Laba sesudah pajak)

(Laba usaha patungan)

(Laba usaha)

(Persetujuan penbagian

laba)

(Laporan rugi laba)

(Pendekatan laba rugi)

(ikhtiar rugi laba)

(Biaya tambahan)

(Biaya tak langsung)

(Biaya departemen tak langung)

(Biaya pabrik tak langsung)

(Tenaga kerja tak langsung) 
INDERECT MATERIAL

INDIRECT OPERATIING EXPENSE

INDIVIDUAL PRIPRIETORSHIP

INFLATION

INFORMATION

INFORMATION SYSTEM

INITIAL INVENTORY

INITIAL AUDIT

INPUT TAX

INSTALLATION COST

INSTALLMENT

INSTALLMENT CONTRACT

RECEIVABLE

INSTALLMENT METHOD

INSTALLMENT PAYABLE

INSTALLMENT TERM DEBT

INSURANCE EXPENSE GENERAL

INSURANCE EXPENSE SELLING

INTAGIBLE ASSET

INTANGIBLE FIXED ASSETS

INTERCOMPANY LOANS

INTEREST

INTEREST BAERING NOTE

INTEREST EXPENSE

INTEREST FACTOR

INTEREST INCOME

INTEREST PAYABLE

INTEREST RECEIVABLE

INTERIM STATEMENT

INTERNAL AUDIT
(Bahan baku tak langsung)

(Biaya usaha tak langsung)

(perusahan perorangan)

(Inflansi)

(informasi)

(Sistem informasi)

(Persediaan awal)

(Pemeriksaan awal/pertama

kali)

(Pajak masukan)

(Biaya instalasi atau

pemasangan)

(Angsuran atau cicilan)

(Piutang penjualan cicilan)

(Metode cicilan)

(Hutang cicilan)

(Utang jangka menengah)

(Biaya asuransi unum)

(Biaya asuransi penjualan)

(Aktiva tak berwujud)

(Aktiva tetap tak berwujud)

(Pinjaman antar perusahan)

( Bunga )

(Wesel berbunga)

(Biaya bunga)

(Faktor bunga)

(Pendapatan bunga)

(Hutang bunga)

(Piutang bunga)

(Laporan sementara)

(Pemeriksan Intern) 
INTERNAL AUDITOR

INTERNAL CONTROL

INTERNAL CONTROL

QUESTIONNAIRE

INTERNAL FINANCING

INVENTORY

INVENTORY BALANCE

INVENTORY OF MERCHANDISE

INVENTORY OF MATERIAL

INVENTORY TRUN OVER

INVENTORY VALUATION

INVESMENT IN FUND

INVESMENT IN BOND

INVESMENT IN JOINT VENTURE

INVESMENT IN LAND

INVESMENT IN LIFE INSURANCE

INVESMENT IN STOCK

INVESTOR

INVOICE

J

JOB ORDER COST

JOB ORDER COST SHEET

JOB ORDER COST SYSTEM

JOB TIME TICKET

JOINT COST
(Pemeriksan internal)

(Pengawasan internal)

(Pertanyaan pengendalian

Intern)

(Pembiayan internal)

(Persediaan)

(Saldo Persedian)

(Persediaan barang

dagangan)

(Persediaan Bahan Mentah)

(Perputaran persediaan)

(Penilaian Persediaan)

(Investasi dalam dana)

(Investasi dalam obligasi)

(Investasi dalam usaha

patungan)

(Investasi dalam bentuk

tanah)

(Investasi dalam bentuk

asuransi jiwa)

(Investasi saham)

Orang yang menanamkan

modal

(Faktur)

(Biaya pesanan)

(Kartu biaya pesanan)

(Sistem biaya pesanan)

(Kartu jam kerja)

(Biaya gabungan) 